\title{
Studi Alternatif Bentuk Rangka Jembatan Canai Dingin Untuk Pejalan Kaki Bentang Kecil Terhadap Rasio Berat dan Lendutan
}

\author{
Afif Navir Refani, Dimas Dibiantara, Munarus Suluch, Ahmad Faqihul Muqoddam \\ Departemen Teknik Infrastruktur Sipil Fakultas Vokasi ITS \\ Email:navir@ce.its.ac.id
}

\begin{abstract}
Currently, founded many non-engineered bridges that are damaged in the remote areas. The alternative to solving the bridge problem in remotes areas for pedestrians is using a truss bridge system with the cold-formed steel material. The truss bridge system is the ideal shape for coldformed steel material that is weak to buckling. This study discusses the effect of different truss shapes to the weight and deflection ratio that occurs due to the pedestrian load on the small span $(L=4 m)$. The proposed truss shape refers to general applied forms that will be developed based on SNI 1725-2016 for loading criteria and cold-formed steel cross-sectional analysis based on SNI 7971-2013. The prototype of truss shape will be tested at the laboratory in model scale. The results of this study will introduce a new truss shape of the cold-formed steel bridge with the smallest deflection
\end{abstract}

Keywords: shape of truss bridge, cold-formed steel, pedestrians, deflection

\begin{abstract}
Abstrak
Pada daerah terpencil banyak ditemui jembatan sederhana (non-engineered bridge) yang mengalami kerusakan. Salah satu alternatif untuk menyelesaikan masalah jembatan pada daerah terpencil untuk pejalan kaki adalah menggunakan jembatan rangka dengan material canai dingin. Jembatan sistem rangka adalah bentuk yang ideal untuk material canai dingin yang rawan mengalami tekuk. Beberapa bentuk jembatan rangka yang banyak diaplikasikan adalah tipe Warren truss, Pratt truss, Howe truss dan K-truss.

Penelitian ini membahas pengaruh bentuk rangka terhadap rasio berat dan lendutan yang terjadi akibat beban pejalan kaki pada bentang pendek $(L=4 \mathrm{~m})$. Dalam pengembangan bentuk rangka ini mengacu pada bentuk rangka yang banyak diaplikasikan, menggunakan pembebanan sesuai SNI 1725-2016 dan analisa penampang canai dingin berdasarkan SNI 79712013. Usulan bentuk rangka yang dihasilkan juga akan dilakukan pengujian beban di laboratorium. Hasil dari penelitian ini diharapkan dapat diusulkan alternatif bentuk rangka baru jembatan canai dingin dengan lendutan yang paling kecil.
\end{abstract}

Kata kunci: bentuk jembatan rangka, canai dingin, pejalan kaki, lendutan

\section{Pendahuluan}

Jembatan merupakan suatu konstruksi bangunan yang memiliki peranan penting untuk menghubungkan antar satu daerah dengan daerah yang lain. Pada daerah terpencil masih banyak kita temui jembatan sederhana (non-engineered bridge) yang biasanya dilewati oleh masyarakat dengan berjalan kaki, dimana hal tersebut dapat membahayakan masyarakat selain umur manfaat jembatan sederhana tersebut yang seringkali tidak panjang dan cepat mengalami kerusakan baik karena beban yang melintas, maupun karena pengaruh alam. Salah satu alternatif untuk menyelesaikan problematika jembatan pada daerah terpencil untuk masyarakat pejalan kaki adalah dengan menggunakan jembatan rangka yang terbuat dari canai dingin (cold formed).

Bahan canai dingin memiliki kelebihan dalam hal kemudahan pelaksanaan karena beratnya ringan dan sistem penyambungannya relatif mudah. Namun karena memiliki berat yang ringan dan 
penampang yang tipis, maka kelemahan utamanya adalah terjadinya tekuk ( $b u c$ $k$ ling). Untuk itu jembatan canai dingin dibuat dengan sistem rangka untuk mengantisipasi efek tekuk.

Jembatan sistem rangka adalah sistem struktur jembatan tersusun dari batang batang profil yang dihubungkan satu sama lain. Batang-batang tersebut disusun sedemikian rupa sehingga akan terjadi gaya aksial tekan ataupun tarik. Dengan meminimalisir momen, maka sistem jembatan rangka ini adalah bentuk yang ideal untuk material canai dingin yang rawan mengalami tekuk. Bentuk jembatan rangka yang banyak diaplikasikan adalah tipe Warren truss, Pratt truss, Howe truss dan K-truss.

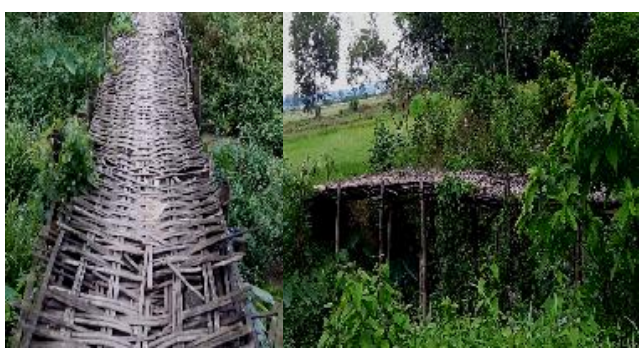

Gambar 1. Jembatan Pejalan Kaki pada Daerah Terpencil

Penelitian ini membahas pengaruh bentuk rangka terhadap rasio berat dan lendutan yang terjadi akibat beban pejalan kaki pada bentang pendek $(L=4 \mathrm{~m})$. Dalam pengembangan bentuk rangka yang diusulkan ini menggunakan dasar pembebanan sesuai SNI 1725-2016 dan analisa penampang canai dingin berdasarkan SNI 7971-2013. Usulan bentuk rangka yang dihasilkan juga akan dilakukan pengujian beban di laboratorium. Hasil dari penelitian ini adalah dapat diusulkannya bentuk rangka baru jembatan canai dingin berdasarkan pengembangan dari bentuk jembatan yang sudah banyak diaplikasikan, dimana jembatan tersebut harus memiliki kriteria lendutan yang paling kecil.

\section{Metodologi}

Adapun metodologi pada penelitian ini sebagai berikut :

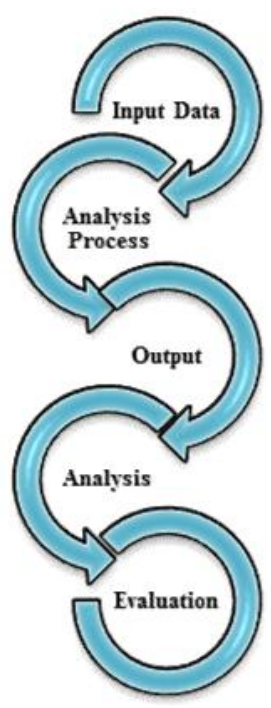

Pada penelitian ini bertujuan utnuk mengetahui bentuk struktur yang efisien dan metode pelaksanaan yang mudah dikerjakan pada jembatan pejalan kaki. Jembatan pejalan kaki untuk penelitian yang pertama ini memiliki spesifikasi sebagai berikut :

- Jenis Jembatan :

Jembatan Rangka Baja Canai Dingin Lantai Kendaraan Atas 
- Bentang Jembatan: 4 meter

- Lembar Jembatan : 0,9 meter

- Lantai Jembatan : Pelat Multiplek $(\mathrm{t}=12 \mathrm{~mm})$

- Tinggi Rangka : 0,6 meter

- Sambungan : Sekrup (12-14 x 20)

Spesifikasi Baja Canai Dingin

- Berat Jenis $\quad: 7850 \mathrm{Kg} / \mathrm{m}^{3}$

- Tegangan Ultimet : $550 \mathrm{MPa}$

- Modulus Elastisitas : $200.000 \mathrm{MPa}$

Proses analisis di lakukan untuk mengetahui performa lendutan struktur jembatan. Analisis struktur juga bertujuan untuk mengetahui gaya yang bekerja pada jembatan serta mengetahui kemungkinan terburuk akibat dari beban-beban yang bekerja. Proses analisa struktur menggunakan program bantu SAP 2000 berdasarkan standar AISI-LRFD 96. Program SAP 2000 mampu menampilkan gaya aksial tekan, gaya aksial tarik, gaya momen yang terjadi serta lendutan berdasarkan kombinasi beban. Hasil yang di tampilkan oleh SAP 2000 ini selanjutkan akan kontrol berdasarkan SNI 7971:2013.

Setelah melakukan analisa struktur akan terpilih model struktur yang efisien dan mudah dikerjakan. Maka perlu di lakukan pengujian laboratorium untuk mengetahui lendutan saat pengujian.

\section{Hasil dan Pembahasan}

Berikut ini hasil dari analisa lendutan beberapa bentuk rangka struktur jembatan pejalan kaki canai dingin dengan bentang kecil ( $\mathrm{L}=4 \mathrm{~m})$ menggunakan program bantu SAP 2000 :

\section{$\underline{\text { Model } 1}$}

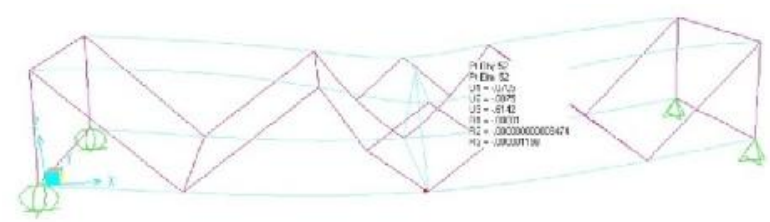

Gambar 1. Model 1

$$
\begin{array}{ll}
\text { Lendutan } & =-0,6113 \mathrm{~mm} \\
\text { Ultimit Tarik } & =3210,53 \mathrm{~kg} \\
\text { Ultimit Tekan } & =7340,16 \mathrm{~kg} \\
\text { Stressing Ratio Tekan } & =0,0711 \\
\text { Stressing Ratio Tarik } & =0,1260 \\
\text { Berat Total } & =53,34 \mathrm{~kg}
\end{array}
$$$$
\text { Rasio Berat/Lendutan }=87,25
$$

\section{Model 2}

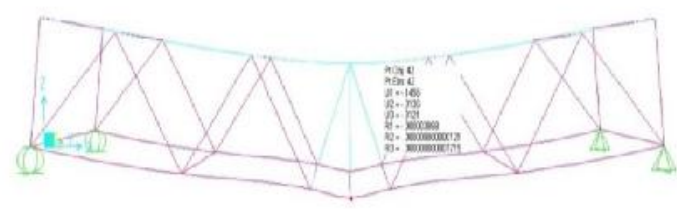

Gambar 2. Model 2

$$
\begin{array}{ll}
\text { Lendutan } & =-0,8121 \mathrm{~mm} \\
\text { Ultimit Tarik } & =3210,53 \mathrm{~kg} \\
\text { Ultimit Tekan } & =7340,16 \mathrm{~kg}
\end{array}
$$$$
\text { Stressing Ratio Tekan }=0,0682
$$$$
\text { Stressing Ratio Tarik }=0,1656
$$$$
\text { Berat Total } \quad=50,87 \mathrm{~kg}
$$

Rasio Berat/Lendutan $=62,64$

\section{$\underline{\text { Model } 3}$}

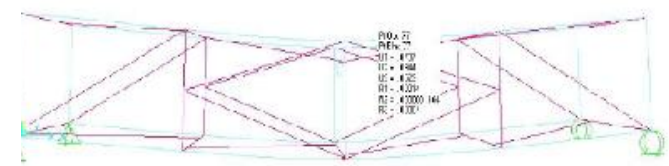

Gambar 4. Model 3 
Lendutan

Ultimit Tarik

$=-0,6523 \mathrm{~mm}$

Ultimit Tekan

$=3210,53 \mathrm{~kg}$

$=7340,16 \mathrm{~kg}$

Stressing Ratio Tekan $=0,0467$

Stressing Ratio Tarik $=0,0918$

Berat Total $=62,12 \mathrm{~kg}$

Rasio Berat $/$ Lendutan $=95,23$

\section{Model 4}

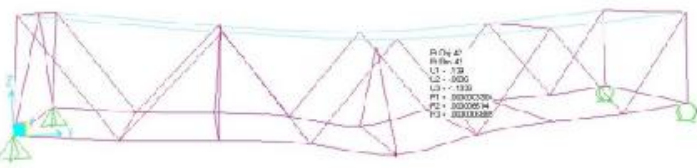

Gambar 5. Model 4

$$
\begin{array}{ll}
\text { Lendutan } & =-1,1036 \mathrm{~mm} \\
\text { Ultimit Tarik } & =3210,53 \mathrm{~kg} \\
\text { Ultimit Tekan } & =7340,16 \mathrm{~kg} \\
\text { Stressing Ratio Tekan } & =0,0595 \\
\text { Stressing Ratio Tarik } & =0,1625 \\
\text { Berat Total } & =47,7 \mathrm{~kg}
\end{array}
$$

Rasio Berat $/$ Lendutan $=43,22$

\section{Model 5}

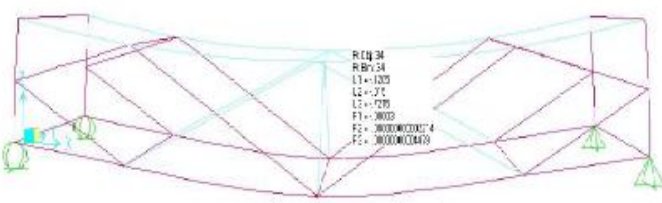

Gambar 6. Model 5

Lendutan

Ultimit Tarik

$$
=-0,7215 \mathrm{~mm}
$$

Ultimit Tekan

$$
=3210,53 \mathrm{~kg}
$$$$
=7340,16 \mathrm{~kg}
$$

Stressing Ratio Tekan $=0,0546$

Stressing Ratio Tarik $=0,1174$

Berat Total

$$
=52,75 \mathrm{~kg}
$$

Rasio Berat $/$ Lendutan $=73,11$

\section{$\underline{\text { Model } 6}$}

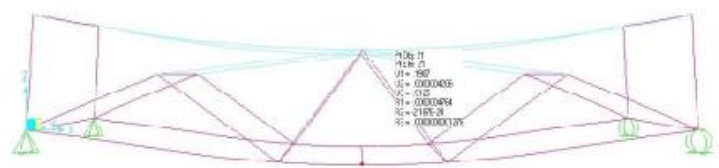

Gambar 7. Model 6

$$
\begin{array}{ll}
\text { Lendutan } & =-0,9215 \mathrm{~mm} \\
\text { Ultimit Tarik } & =3210,53 \mathrm{~kg} \\
\text { Ultimit Tekan } & =7340,16 \mathrm{~kg}
\end{array}
$$

Stressing Ratio Tekan $=0,0669$

Stressing Ratio Tarik $=0,1735$

Berat Total $\quad=47,67 \mathrm{~kg}$

Rasio Berat $/$ Lendutan $=51,73$

\section{$\underline{\text { Model } 7}$}

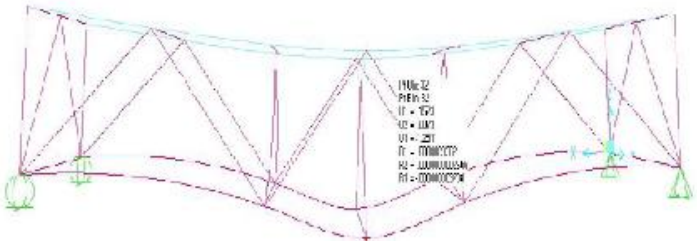

Gambar 8. Model 7

$$
\begin{array}{ll}
\text { Lendutan } & =-0,7346 \mathrm{~mm} \\
\text { Ultimit Tarik } & =3210,53 \mathrm{~kg} \\
\text { Ultimit Tekan } & =7340,16 \mathrm{~kg}
\end{array}
$$

Stressing Ratio Tekan $=0,0555$

Stressing Ratio Tarik $=0,1629$

Berat Total $\quad=48,02 \mathrm{~kg}$

Rasio Berat $/$ Lendutan $=65,37$

\section{$\underline{\text { Model } 8}$}

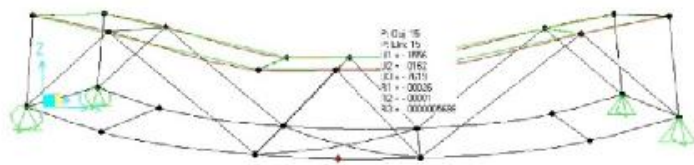

Gambar 9. Model 8 
Lendutan

Ultimit Tarik

$=-0,7253 \mathrm{~mm}$

Ultimit Tekan

$=3210,53 \mathrm{~kg}$

$=7340,16 \mathrm{~kg}$

Stressing Ratio Tekan $=0,0452$

Stressing Ratio Tarik $=0,1689$

Berat Total

$=43,38 \mathrm{~kg}$

Rasio Berat $/$ Lendutan $=59,81$

Pengujian Laboratorium

Hasil model yang terpilih selanjutnya akan dilakukan pengujian di laboratorium dengan beban tekan $500 \mathrm{~kg}$ di tengah bentang dan diukur lendutannya disisi bawah jembatan dengan dial gauge.

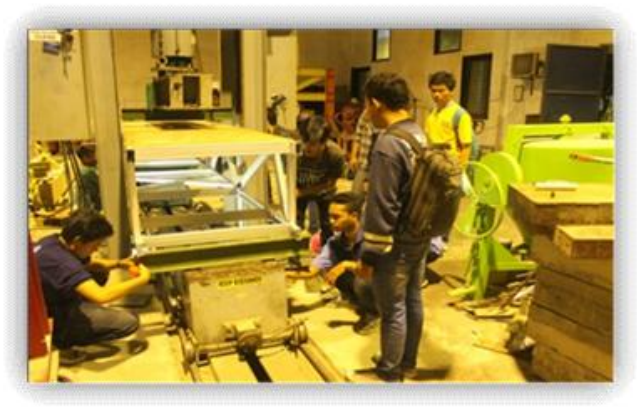

Gambar 10. Pengujian Model Jembatan di Laboratorium

Hasil dari pengujian laboratorium adalah sebagai berikut:

- Pengujian 1

Lendutan $=4 \mathrm{~mm}$

- Pengujian 2

Lendutan $=2,6 \mathrm{~mm}$

- Pengujian 3

Lendutan $=3,6 \mathrm{~mm}$

Lendutan Rata-Rata $=3,4 \mathrm{~mm}$

\section{Kesimpulan}

Berdasarkan penelitian ini maka dapat disimpulkan sebagai berikut:

1. Konsep struktur segitiga pada model struktur jembatan lebih efisien daripada model yang lain karena lebih stabil.

2. Model rangka jembatan yang paling optimum berdasarkan rasio berat dan lendutan adalah model no.8 dimana lendutan teoritisnya adalah $0,7253 \mathrm{~mm}$ dengan berat jembatan $43,38 \mathrm{~kg}$.

3. Lendutan rencana ialah sebesar 1,7 $\mathrm{mm}$ dan lendutan lab/lapangan sebesar 3,4 $\mathrm{mm}$ dan lendutan ijin 5 $\mathrm{mm}$, berarti memenuhi syarat lendutan ijin.

4. Penelitian ini memiliki batas panjang jembatan $4 \mathrm{~m}$, untuk penelitian selanjutnya akan di lakukan penelitian dengan panjang jembatan $4 \mathrm{~m}, 8 \mathrm{~m}$, dan $16 \mathrm{~m}$ dengan model struktur pada model 3 (model terpilih).

\section{Daftar Pustaka}

Badan Litbang PU Departemen Pekerjaan Umum. 2013. Perencanaan Struktur Baja Canai Dingin (SNI 7971-2013). Jakarta: Badan Standardisasi Nasional (BSN).

Badan Litbang PU Departemen Pekerjaan Umum. 2002. Perencanaan Struktur Baja Dengan Metode LRFD (SNI 03-1729-2002). 
Jurnal Aplikasi Teknik Sipil ISSN.1907-753X

Jakarta: Badan Standardisasi Nasional (BSN).

Badan Litbang PU Departemen Pekerjaan Umum. 2005. Standart Pembebanan Untuk Jembatan (RSNI T-02-2005). Jakarta: Badan Standardisasi Nasional (BSN).

PT. Gunung Raja Paksi, LippedChannel (http://grdsteel.com/images/stori es/product/grp/lippedchannel.pd f, diakses 12 September 2016).
Schafer, B.W. 2006. "Designing Cold Formed Steel Using The Direct Streght Method. "Proceeding of 18th International Specialty Conference On Cold Formed Steel Structure. Florida 26-27 October.

Wei wen yu. 2000. Cold Formed Steel Design Third Edition. University of Missouri Rolla 